ARTICLE

\title{
From amino acid mixtures to peptides in liquid sulphur dioxide on early Earth
}

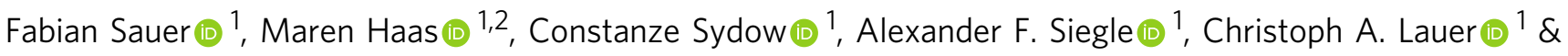 \\ Oliver Trapp (1) 1,2四
}

The formation of peptide bonds is one of the most important biochemical reaction steps. Without the development of structurally and catalytically active polymers, there would be no life on our planet. However, the formation of large, complex oligomer systems is prevented by the high thermodynamic barrier of peptide condensation in aqueous solution. Liquid sulphur dioxide proves to be a superior alternative for copper-catalyzed peptide condensations. Compared to water, amino acids are activated in sulphur dioxide, leading to the incorporation of all 20 proteinogenic amino acids into proteins. Strikingly, even extremely low initial reactant concentrations of only $50 \mathrm{mM}$ are sufficient for extensive peptide formation, yielding up to $2.9 \%$ of dialanine in 7 days. The reactions carried out at room temperature and the successful use of the Hadean mineral covellite (CuS) as a catalyst, suggest a volcanic environment for the formation of the peptide world on early Earth.

\footnotetext{
${ }^{1}$ Department of Chemistry and Pharmacy, Ludwig-Maximilians-University, Butenandtstr. 5-13, 81377 Munich, Germany. ${ }^{2}$ Max-Planck-Institute for Astronomy, Königstuhl 17, 69117 Heidelberg, Germany. ${ }^{凶}$ email: oliver.trapp@cup.uni-muenchen.de
} 
B ecause of the great variety of functions peptides can perform in nature, the formation of peptides from amino acids is irreplaceable for life as we know it ${ }^{1}$. This reaction plays a key role in the cellular function as well as in the origin of life. Several likely scenarios for prebiotic amino acid syntheses have been proposed ${ }^{2-5}$. In addition, amino acids have been identified on meteorites ${ }^{6-9}$. The original peptide synthesis from prebiotic material is being intensively researched today and numerous possible synthetic pathways have been proposed. The formation of peptides from amino acids is not readily performed in aqueous solution because condensation reactions are thermodynamically unfavourable under these conditions. Proposed scenarios to overcome this barrier include drying of amino acid mixtures ${ }^{10,11}$, mineral surface catalysis ${ }^{12-14}$, co-condensation with $\alpha$-hydroxy acids ${ }^{15,16}$, polymerization of activated amino acid derivatives ${ }^{17-19}$, and solvent-free mechanochemical environments ${ }^{20}$. In salt induced peptide formation (SIPF), highly concentrated saline solutions provide dehydrating conditions, while additional metal ions, preferably copper(II), further enhance the kinetics of peptide formation ${ }^{21,22}$. Recent studies indicate that the salt concentration, altered by wet and dry cycles $^{23}$, might have supported the formation of cell membranes leading to protocells ${ }^{24}$. Furthermore, the salt composition can regulate, for example, the activity of RNA such as self-replication and extension ${ }^{25}$. The availability of copper(II) depends on the oxidation state of the Hadean atmosphere and would only have been possible at oxygen partial pressures of $10^{-35} \mathrm{~atm}^{26}$. Several copper minerals are assumed to have been present on the early Earth, particularly sulfides such as covellite $(\mathrm{CuS})^{27}$.

To circumvent the thermodynamic barrier in aqueous solution, other solvents were also considered for prebiotic peptide formation. Some alternatives such as volcanic, magmatic conditions ${ }^{28}$, formamide as solvent ${ }^{29,30}$, or eutectic solutions have been examined in the past ${ }^{31,32}$. Moreover, sulphur dioxide $\left(\mathrm{SO}_{2}\right)$ has gained attention as a prebiotically available compound in recent years, as it has been released in significant amounts into the atmosphere by volcanic outgassing and is also present in large quantities in other celestial bodies ${ }^{33-35}$.

The question about the reaction conditions at the time of the origin of life is highly complex ${ }^{36}$ and geochemical data are not available, because almost no rock samples from the Hadean eon are available ${ }^{37}$ and it would be highly difficult to estimate the atmospheric pressure from them. Also, about the prevailing temperature, no certain prediction can be made at the present time since it depends substantially on the composition and chemical transformations of the atmosphere. Apart from the general assumptions about the conditions during the emergence of life ( 200-800 Ma), the possibility of different, location-dependent conditions can be considered. Furthermore, seasons and different microhabitats ${ }^{38}$ similar to today's Earth are conceivable. In recent years, detailed models to simulate the change of the atmospheric and environmental conditions of the early Earth $^{39}$ were developed.

Models predict that the probability that the surface temperature of the Earth was less than $273.15 \mathrm{~K}$ is $67 \%$ at $200 \mathrm{Ma}$; thus, the climate was cold because of the consumption of $\mathrm{CO}_{2}$ by ejecta weathering ${ }^{40}$, which could lead to the conditions of a (soft) snowball Earth. There is evidence from samples with negative carbon isotope anomalies in carbonate rocks in Namibia for the existence of a snowball Earth later in the Earth's history, in the Paleoproterozoic $(2.5 \mathrm{Ga})^{41,42}$. The atmospheric pressure ranges from $\sim 0.01$ to 100 bar $^{43,44}$. It is also assumed that a large amount of the Earth's inventory of nitrogen was in the atmosphere with a partial pressure $\mathrm{p}\left(\mathrm{N}_{2}\right)$ of $\sim 0.8$ bar $^{43}$ or even $2-3 \mathrm{bar}^{44} . \mathrm{SO}_{2}$ has a boiling point of $-10^{\circ} \mathrm{C}$ at 1 bar. The here discussed geochemical models suggest the possibility of temporal phases or local environments on the early Earth, where $\mathrm{SO}_{2}$ existed in liquid form. In addition, high concentrations of $\mathrm{SO}_{2}$ near volcanoes on the Hadean Earth ${ }^{45,46}$ increased the local partial pressure of $\mathrm{SO}_{2}$. The influence of $\mathrm{SO}_{2}$ has been studied in various prebiotic reactions, but mostly sulfite salts in water were used instead of liquid $\mathrm{SO}_{2}{ }^{47-51}$.

Systems of higher complexity are of particular interest in the formation of peptides, as they allow the preferential formation of specific peptide sequences, functional polymers, and even their further enrichment ${ }^{52}$. Prebiotic amino acid syntheses also typically lead to a variety of products ${ }^{3}$, whose conversion results in a high diversity of peptides, depending on the reaction conditions. In recent studies, however, often only a limited number of amino acids are used simultaneously in the syntheses. The use of a larger number of amino acids in the same reaction reveals many additional aspects of the synthesis method under investigation, including frequent by-products or lack of compatibility with the reaction conditions or the other amino acids. On the other hand, it also reveals the selectivity to form certain peptides whose sequence may have greater potential for functionality due to the greater likelihood of formation.

In the present work, we investigate condensed $\mathrm{SO}_{2}$ as an alternative hygroscopic solvent compared with aqueous salt solutions for prebiotic peptide formation. Large mixtures of amino acids are reacted in both systems and the resulting product distributions are compared. It is shown that the different environments produce varying selectivity in the peptide sequences. However, peptide condensation in $\mathrm{SO}_{2}$ proceeds under simpler conditions, at room temperature and with low amino acid and metal catalyst loadings. Di- to tetrapeptides are formed and, importantly, all 20 amino acids can be incorporated.

\section{Results}

Peptide formation in sulphur dioxide. Although the advantages of pure liquid $\mathrm{SO}_{2}$ as a solvent in organic synthesis are well known ${ }^{53}$, its use in the search for peptide formation reactions under prebiotic conditions has not yet been considered. Starting with the simplest amino acids glycine $(G)$ and L-alanine (A), we investigated the possibility of efficient peptide condensation in liquid $\mathrm{SO}_{2}$ by metal catalysis. For this purpose, the two amino acids were mixed with $\mathrm{CuCl}_{2}$ in a pressure apparatus, $\mathrm{SO}_{2}$ was added, and the mixture was stirred for 1-21 d at room temperature. The reaction mixture was analyzed by capillary electrophoresis (CE) and high-pressure liquid chromatography (HPLC), both coupled with high-resolution mass spectrometry (HR-MS). No peptides were observed without $\mathrm{CuCl}_{2}$ as additive. When $\mathrm{CuCl}_{2}$ was added, glycylglycine (GG) was already formed after $1 \mathrm{~d}$; alanine-containing dipeptides as well as traces of the tripeptide GGG were detected after $7 \mathrm{~d}$. Longer reaction times led to a further increase in peptide products. The cyclic diketopiperazines, which are often observed as a by-product in peptide condensation reactions ${ }^{54}$, were not detected.

The next step was to investigate the effect of additives to the reaction mixture. High amounts of $\mathrm{NaCl}$ enable the SIPF reaction in water and were therefore also investigated in this context. $\mathrm{NaCl}$ did not increase the reactivity, on the contrary, it inhibited the product formation at high salt concentrations, similar to the reaction in water.

Another additive that was investigated is urea. Its prebiotic synthesis has already been described ${ }^{55,56}$. Urea has already been used as a condensation agent in prebiotic phosphorylation reactions with nucleosides ${ }^{57-59}$. The exact mechanism of the enhancing effect is not clear, but the hydrolysis of urea and the formation of reactive intermediate species are under discussion ${ }^{57}$. In addition, urea is known to form strong hydrogen bonds, 

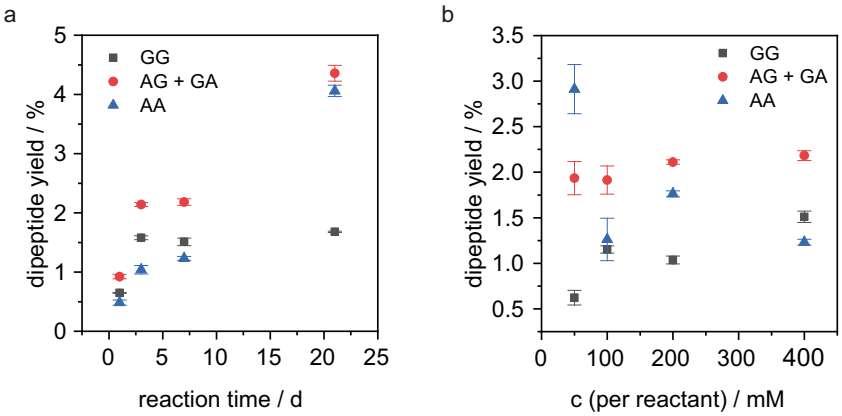

Fig. 1 Dipeptide yields in $\mathbf{S O}_{\mathbf{2}}$. a Peptide yields in dependence of the reaction time are shown with initial $A, G$, and $\mathrm{CuCl}_{2}$ concentrations of $400 \mathrm{mM}$. b Peptide yields in dependence of the initial amino acid and $\mathrm{CuCl}_{2}$ concentrations after $7 \mathrm{~d}$ are displayed. Error bars are \pm s.d. after two measurements.

denature proteins, and remove water from the hydration shell of proteins ${ }^{60}$. A positive effect of urea on peptide condensation through the formation of reactive intermediates or as a dehydrating agent is therefore conceivable. In fact, the addition of urea to peptide formation in $\mathrm{SO}_{2}$ not only led to an enhancement of already detected peptide signals, but it also supported the formation of the previously undetected tripeptides AAA, AAG, and AGG. The use of urea without a metal catalyst did not lead to peptide formation. Thus, urea does not catalyze the reaction itself, but promotes it as a condensation agent. For the further investigations, an equivalent of urea was added to all reactions. The peptide yields as a function of reaction time are shown in Fig. 1a. Significant amounts of dipeptides were already formed after $1 \mathrm{~d}$ and, except for GG, the yields increased from then until $21 \mathrm{~d}$. The concentration of GG remained rather constant after $3 \mathrm{~d}$, but significant amounts of tripeptides also appeared after $7 \mathrm{~d}$. It is possible that GG is converted to tripeptides more rapidly than the other dipeptides.

A critical point in prebiotic reactions is often the required high concentration of reactants, which cannot be reconciled with a dilute ocean or pond on early Earth. We started the reaction with a typical concentration of $400 \mathrm{mM}$ per amino acid and $\mathrm{CuCl}_{2}$, but also tested lower concentrations of $200 \mathrm{mM}, 100 \mathrm{mM}$, and $50 \mathrm{mM}$. Contrary to our expectations, the reaction was favoured at lower concentrations, leading to the formation of more tri- and even tetrapeptides at $50 \mathrm{mM}$ after $21 \mathrm{~d}$ (Supplementary Figs. 41-44). Figure $1 \mathrm{~b}$ shows the dipeptide yields after $7 \mathrm{~d}$ as a function of the initial amino acid and $\mathrm{CuCl}_{2}$ concentrations. With decreasing amino acid concentration, the dipeptide yields remained constant. The maximum yield for AA was observed at an initial reactant concentration of $50 \mathrm{mM}$, suggesting effective peptide synthesis even in dilute solutions. Furthermore, significant amounts of tri- and tetrapeptides could be detected after $21 \mathrm{~d}$. To further investigate the reaction in dilute solutions, we also reduced the catalyst loading. If the metal salt was not used stoichiometrically, but in $1 \mathrm{~mol} \%$, the reaction still led to dipeptide formation.

To further test the plausibility of the reaction under prebiotic conditions, we replaced the synthetic $\mathrm{CuCl}_{2}$ catalyst with a natural sample of the copper(II) mineral covellite (CuS). Covellite is one of the 13 copper minerals, which may have been present in the Hadean and constituted $2.1 \%$ of the prebiotic mineral inventory ${ }^{24}$. It is assumed that covellite was formed by hydrothermal alteration and is one of the plausible copper minerals prior to significant near-surface oxidation ${ }^{24}$. With mineral catalysis in the presence of urea, dipeptides GG, AA, $\mathrm{GA}$ and $\mathrm{AG}$ were formed from $400 \mathrm{mM} \mathrm{A}$ and $\mathrm{G}$ after $7 \mathrm{~d}$
(Supplementary Fig. 19). The amounts of dipeptides formed were about one-tenth of those obtained with synthetic $\mathrm{CuCl}_{2}$ as catalyst. Tripeptides were not detected. Covellite thus catalyzes the reaction, despite a somewhat slower turnover, supporting the importance of this reaction scenario for the early Earth.

Application to large amino acid mixtures. Prebiotic peptide formation is often tested for only a limited number of amino acids. If many compounds are used, however, they are usually tested individually in separate reactions rather than in a mixture. However, these concepts overlook the dynamics and possible interactions of all amino acids with each other, which must inevitably also have taken place under the complex conditions of the early Earth. Therefore, the study of complex larger systems is becoming increasingly important. This approach allows the whole spectrum of products to be studied under specific reaction conditions and compared with others. The development of more sophisticated analytical tools allows the detailed study of the immense number of products generated during peptide condensation (peptide coupling of all proteinogenic amino acids with each other already yields 400 possible dipeptide and 8000 tripeptide sequences). The combination of efficient CE separations with fast, high-resolution mass analyzers is a powerful tool of increasing relevance and is often used for the precise analysis of protein mixtures $^{61}$. To this end, we have recently developed a straightforward sheath-flow CE-MS interface for separation with high-sensitivity Orbitrap mass detection ${ }^{62}$. Tandem MS measurements (MS/MS) were performed to verify the detected peptides and determine peptide sequences.

After identifying $\mathrm{SO}_{2}$ as an interesting alternative solvent for prebiotic peptide condensation and optimizing the reaction conditions, we extended the system to the complete set of 20 proteinogenic amino acids. In this way, the formation of any peptide in question is possible, and thus a meaningful evaluation of the system is achievable. For a conclusive interpretation of the results, we compared the dipeptide mixtures formed with those of the corresponding reaction under equivalent conditions in aqueous solution. We observed the same positive effect of urea on peptide formation in aqueous solution, so it was added to the initial SIPF conditions. Thus, the reaction time, the initial amino acid and urea concentration, and the sample concentration during analysis were identical in both solvents. However, in a few cases, the conditions differed based on previous findings: in the SIPF reaction, $\mathrm{CuCl}_{2}$ and $\mathrm{NaCl}$ cannot be used in stoichiometric amounts, as there are threshold concentrations that must be present for product formation to occur at all. As shown earlier, even minute amounts of $\mathrm{CuCl}_{2}$ induce peptide formation in $\mathrm{SO}_{2}$ and the hygroscopic environment is sufficient to make $\mathrm{NaCl}$ obsolete. Therefore, fixed $\mathrm{CuCl}_{2}$ and $\mathrm{NaCl}$ concentrations of $400 \mathrm{mM}$ and $4.4 \mathrm{M}$ were used in water, while stoichiometric amounts of $\mathrm{CuCl}_{2}$ were used in $\mathrm{SO}_{2}(1 / n$ equivalents for mixtures of $n$ amino acids). $\mathrm{NaCl}$ was not used at all. Furthermore, room temperature has been shown to be sufficient for a successful reaction in $\mathrm{SO}_{2}$, whereas a temperature of $85^{\circ} \mathrm{C}$ is used in water.

Thus, in addition to the complete set of 20 proteinogenic amino acids, four subgroups were analyzed as a function of sidechain properties. The amino acids were divided into a nonpolar, polar-neutral, alkaline, and acidic group and analyzed separately (Fig. 2). In addition, a selected mixture of amino acids that were probably first present on the early Earth ${ }^{63,64}$ was examined. The total concentration of amino acids and urea was maintained at $400 \mathrm{mM}$ in all cases and samples were taken after $7 \mathrm{~d}$ and $21 \mathrm{~d}$.

The reaction of the nonpolar mixture in $\mathrm{SO}_{2}$ yielded every possible dipeptide of the product spectrum (Fig. 3a). After $7 \mathrm{~d}$, few valine-containing dipeptides were not yet formed, but these 

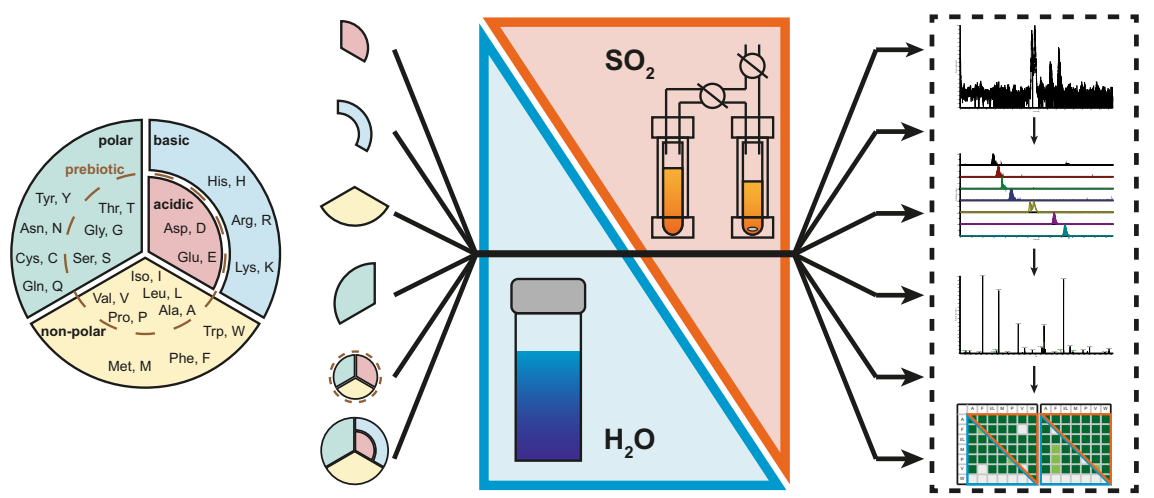

Fig. 2 Experimental and analytical routine. The proteinogenic amino acids were divided into subgroups based on their properties. Each of these subgroups reacted under the same reaction conditions with an overall amino acid concentration of $400 \mathrm{mM}$ in $\mathrm{SO}_{2}$ and water. In addition, the complete set of the proteinogenic amino acids was used in two different overall amino acid concentrations ( $400 \mathrm{mM}$ and $50 \mathrm{mM}$ ). After electrophoretic separation of the reaction mixtures after 7 and $21 \mathrm{~d}$, the resulting dipeptides were confirmed by tandem mass spectrometry allowing for a thorough comparison of the product distribution.

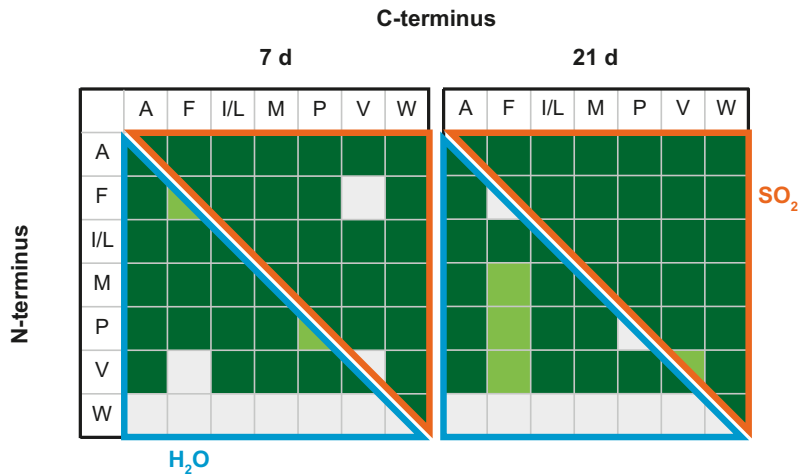

b

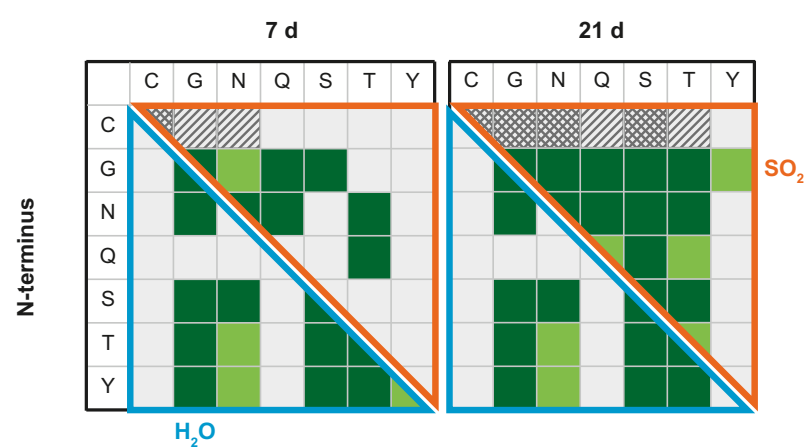

Fig. 3 Product spectrum of the nonpolar and polar-neutral amino acid mixture. Comparison of the detected dipeptides of copper-catalyzed peptide condensation in $\mathrm{SO}_{2}$ and water after 7 and $21 \mathrm{~d}$ starting from the nonpolar (a) or polar-neutral (b) mixture (dark green = confirmed by MS/ MS, light green $=$ traces, white $=$ not detected, cross-hatched $=$ cystine peptides confirmed by MS/MS, hatched=cystine-peptide traces). Amino acids are represented corresponding to the one-letter code.

appear after $21 \mathrm{~d}$. Similarly, most of the possible products are also formed in aqueous solution. However, tryptophan (W) shows low stability in solution and is susceptible to side reactions, especially in combination with metals or high temperatures ${ }^{65}$. After $7 \mathrm{~d}$, this amino acid was rarely detected, and accordingly, dipeptide formation of $\mathrm{W}$ in aqueous solution occurred only very rarely. Apart from this, traces of tripeptides were detected in both reaction media.
The polar-neutral mixture was less reactive in both reaction media (Fig. 3b). In $\mathrm{SO}_{2}$, tyrosine (Y) showed less reactivity, possibly due to its low solubility in the absence of acidic or basic conditions. The formation of dipeptides containing cysteine $(\mathrm{C})$ could not be observed, however, its oxidation to cystine could be confirmed by MS/MS (for MS data, see Supplementary Fig. 38). Furthermore, cystine formed peptide bonds with other polar amino acids as both $\mathrm{N}$ - and C-terminal residues (Supplementary Fig. 39). Apart from this, all dipeptides were observed after $21 \mathrm{~d}$. In aqueous solution, no cysteines could be detected either, but no disulfide bridges were formed here. Furthermore, the hydrolysis of asparagine $(\mathrm{N})$ and glutamine $(\mathrm{Q})$ to the respective acidic amino acids aspartic acid (D) and glutamic acid (E) led to a rapid decrease in their concentration. This strongly inhibited dipeptide formation with $Q$ in particular. Small amounts of tripeptides could be detected in both reaction media, especially those containing two glycine molecules. Importantly, they were formed in higher amounts in $\mathrm{SO}_{2}$, so that their sequence determination was possible (GGG, GGN, NGG, GGQ, QGG, GGS, GSG, SGG, GGT, GTG, and TGG).

For the alkaline and acidic mixtures, almost all possible dipeptides could be detected. The aqueous alkaline mixture showed a strong preference for the incorporation of lysine, as no other dipeptides were confirmed. No tripeptide formation was detected in either solvent (Supplementary Figs. 24-27).

In both media, numerous dipeptides were formed from the prebiotic mixture containing the amino acids proline $(\mathrm{P})$, serine (S), threonine $(\mathrm{T})$, leucine $(\mathrm{L})$, isoleucine $(\mathrm{I}), \mathrm{A}, \mathrm{D}, \mathrm{E}, \mathrm{G}$, and $\mathrm{V}$, which were predominant on the early Earth (Fig. 4). The acidic amino acids were less favoured for incorporation, especially in $\mathrm{SO}_{2}$. Instead, $\mathrm{G}, \mathrm{I}$, and $\mathrm{L}$ were the most reactive in both solvents, as well as $\mathrm{P}$ in $\mathrm{SO}_{2}$ and $\mathrm{V}$ in water. The preference of one sequence over the inverted sequence was observed for several peptides (e.g., VT $>$ TV, DG $>$ GD). The complete dipeptide product tables with differentiation of the peptide sequences can be found in the supplementary information (Supplementary Figs. 19-36).

Finally, we performed the reaction with all 20 proteinogenic amino acids to investigate the reactivity of the overall system (Fig. 5). Some trends from the smaller subgroups remained in the overall mixture, while new observations were also made. In water, the lack of reactivity of $\mathrm{W}, \mathrm{Q}, \mathrm{C}$, and $\mathrm{H}$ was still noticeable. In contrast, $\mathrm{Y}$ and the acidic amino acids were rather inactive in $\mathrm{SO}_{2}$. Cysteine formed few dipeptides, but oxidation to cystine and further condensation with other amino acids was repeatedly observed. In both solvents, many dipeptides with amino acids I, L, 
$\mathrm{G}, \mathrm{V}$, and $\mathrm{K}$ were detected. Other dipeptides were preferentially formed in one of the two environments (e.g., $\mathrm{D}$ was more reactive in water, while $\mathrm{P}$ and $\mathrm{H}$ were more reactive in $\mathrm{SO}_{2}$ ). The composition of the amino acid mixture also affected product formation. The high activity of $\mathrm{V}$ in the total mixture was not predictable from the observations we made in the nonpolar mixture. In $\mathrm{SO}_{2}, \mathrm{~V}$ was the least reactive amino acid, while $\mathrm{W}$ formed fewer peptides in the total mixture. In water, far fewer dipeptides of phenylalanine (F) could be detected in the total mixture than in the subgroup. Because the amino acid concentration in all reactions was always related to the total number of amino acids, the concentration of a single amino acid in the total mixture was lower than in the other mixtures. Therefore, some dipeptides were formed in the subgroups and not in the total mixture (e.g., MI, ST, HH, and DD), and this effect was more pronounced in water than in $\mathrm{SO}_{2}$. To investigate

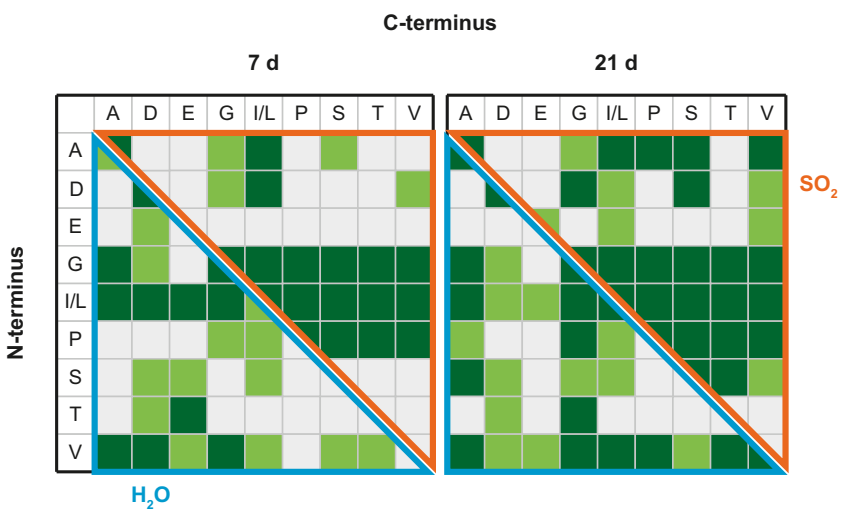

Fig. 4 Product spectrum of the prebiotic amino acid mixture. Comparison of the detected dipeptides of copper-catalyzed peptide condensation in $\mathrm{SO}_{2}$ and water after 7 and $21 \mathrm{~d}$ starting from the prebiotic amino acid mixture (dark green = confirmed by MS/MS, light green = traces, white = not detected). Amino acids are represented corresponding to the oneletter code. this finding in more detail, we performed the reactions of the total mixture at a lower initial amino acid concentration $(50 \mathrm{mM}$ versus $400 \mathrm{mM}$ total concentration, $2.5 \mathrm{mM}$ versus $20 \mathrm{mM}$ per amino acid). The previous experiments already showed that high yields can be obtained in $\mathrm{SO}_{2}$ even at these low concentrations. However, it is only in comparison with the reaction in aqueous solution that the full potential of $\mathrm{SO}_{2}$ becomes obvious (Fig. 5). In water, only very limited peptide formation is possible, resulting in remarkably few dipeptides. In $\mathrm{SO}_{2}$, fewer peptides were detected, but nevertheless, peptide formation was observed for almost all amino acids, which demonstrates the effective reaction conditions impressively.

\section{Discussion}

The formation of functional oligomer chains from single monomer building blocks remains one of the fundamental challenges that must be pursued to understand the evolution of life. In this study, we have presented an alternative reaction medium to circumvent the often discussed thermodynamically inhibited peptide condensation in aqueous environments. On the early Earth, $\mathrm{SO}_{2}$ was released by volcanic emissions. As discussed in the "Introduction", geochemical models suggest the possibility of temporal phases or local environments where $\mathrm{SO}_{2}$ existed as a liquid. This motivates consideration of liquid $\mathrm{SO}_{2}$ as a prebiotic solvent. In our study, we were able to demonstrate effective peptide coupling by metal catalysis up to tetrapeptides starting from single amino acids.

The diverse functions that a peptide can fulfill are determined solely by its sequence. The use of many different amino acids enables the formation of an even greater variety of peptides and peptide sequences. To our knowledge, the simultaneous conversion and detailed analysis of the complete set of all proteinogenic amino acids under prebiotic conditions has not been studied before. The results of this study show that the reactivity of amino acids cannot be considered in isolation. The investigation of large mixtures reveals effects that would have been overlooked in reactions of single amino acids. In both environments studied, it was shown that the reactivity of the individual amino acid can
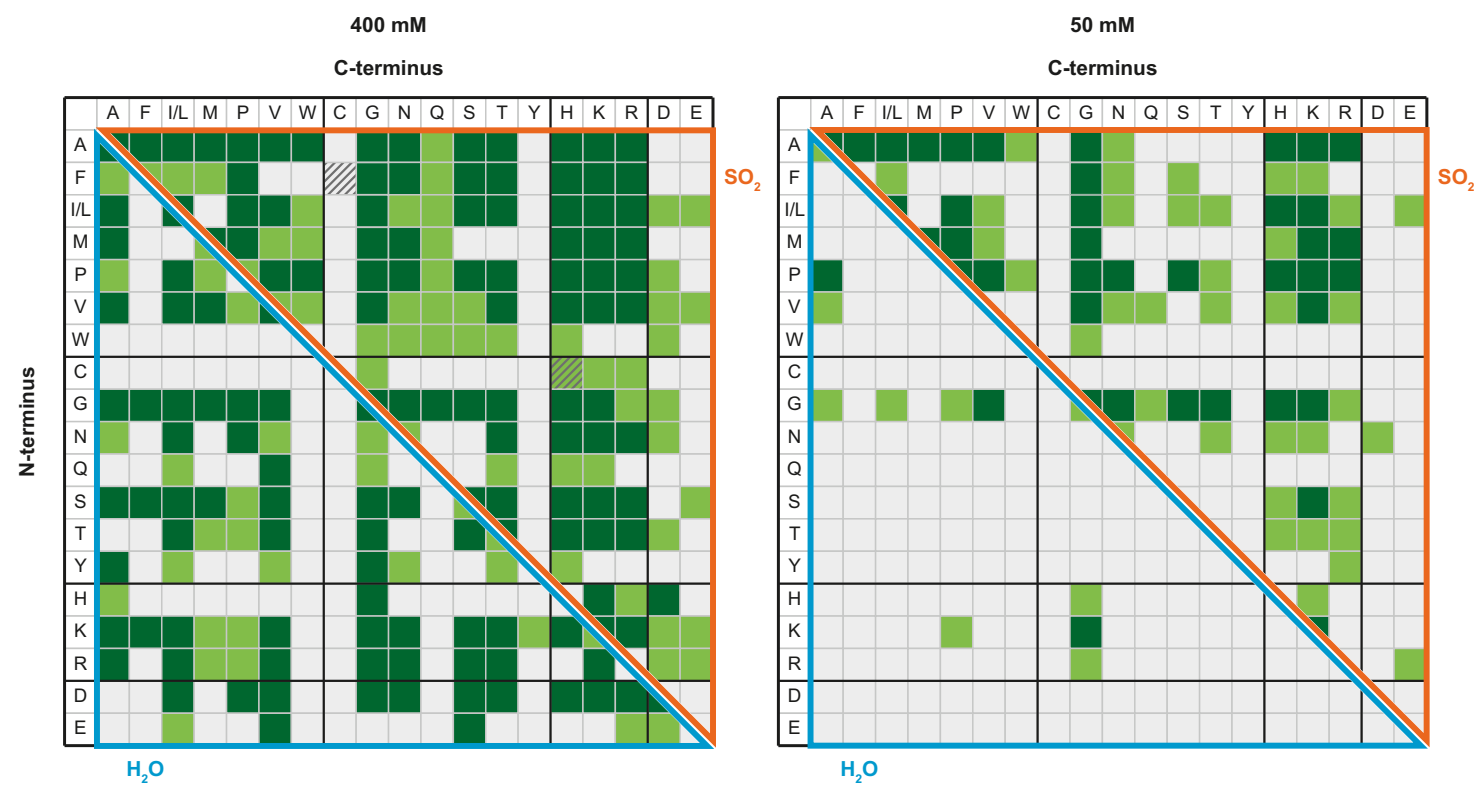

Fig. 5 Product spectrum of the complete amino acid mixture. Comparison of the detected dipeptides of copper-catalyzed peptide condensation in $\mathrm{SO}_{2}$ and water after $21 \mathrm{~d}$ starting from $400 \mathrm{mM}$ or $50 \mathrm{mM}$ of the complete set of proteinogenic amino acids (dark green=confirmed by MS/MS, light green $=$ traces, white $=$ not detected, hatched $=$ cystine-peptide traces). The $\mathrm{CuCl}_{2}$ concentration in $\mathrm{SO}_{2}$ was 5 mol\% in both experiments. Amino acids are represented corresponding to the one-letter code. 
depend on the mixture in which it is used. In $\mathrm{SO}_{2}, \mathrm{~V}$ was the least-reactive amino acid in the nonpolar mixture. In the total mixture, however, it showed increased reactivity compared with W. Furthermore, it became clear that V showed exceptionally good overall reactivity with the other amino acids. A similar observation could be made for $\mathrm{E}$, which showed increased reactivity in the total mixture in $\mathrm{SO}_{2}$ compared with the prebiotic mixture. The results show that there are cooperative effects between different amino acids, which could arise from interactions between the different side groups. For example, the hydroxyl group of $\mathrm{S}, \mathrm{T}$, or $\mathrm{Y}$ could form a temporary ester bond with another amino acid, thereby promoting the formation of an amide bond through an energetically favoured ester-amide exchange. This effect has already been observed in the formation of depsipeptides ${ }^{15,16}$. Furthermore, the catalytic activity of especially glycine and histidine in peptide formation of other amino acids has been observed in other studies ${ }^{22}$. In the proposed mechanism, the catalytically active amino acid promotes the formation of a mixed tripeptide and the following cleavage of it leaves a homo-dipeptide of the other amino acid.

Furthermore, a detailed comparison of the two environments investigated could be made by applying large mixtures of amino acids. The addition of urea led to increased dipeptide detection in both solvents. The comparison of the resulting dipeptide product distributions showed distinctive differences of amino acid activities in the two solvents. In water, for $\mathrm{W}, \mathrm{Q}, \mathrm{C}$ and $\mathrm{H}$ only a low reactivity could be observed. $\mathrm{W}, \mathrm{Q}$ and $\mathrm{N}$ exhibit a low stability in the environment of the SIPF in which $\mathrm{Q}$ and $\mathrm{N}$ are hydrolyzed to the respective acidic amino acids. The corresponding dipeptides could only be observed in a few cases. On the other hand, the acidic amino acids $\mathrm{D}$ and $\mathrm{V}$ showed a high reactivity in water. In $\mathrm{SO}_{2}$, rather poor reactivity of the acidic amino acids was noted. Furthermore, only traces of $\mathrm{Y}$ seem to be soluble in $\mathrm{SO}_{2}$ and accordingly, only few dipeptides of those dipeptides could be detected in the reaction mixtures. However, the formation of cysteines and cystine could only be observed in $\mathrm{SO}_{2}$. Interestingly, after oxidation to cystine, a further reaction to cystine tripeptides could be confirmed, providing sulfur bridges and the possibility for additional structural elements. Noteworthy is the increased formation of proline peptides, which are known for their catalytic activity ${ }^{66}$. Most importantly, each of the 20 amino acids could be incorporated into $\mathrm{SO}_{2}$, which could not be shown for the SIPF reaction. In general, the reaction conditions in $\mathrm{SO}_{2}$ led to a higher reactivity of the amino acids and a greater variety of products. However, the superiority of the solvent is not only reflected in the increased reactivity of the reactants but is particularly evident when compared with the corresponding reaction conditions in water, which differ in several crucial aspects. Most striking is the efficiency of peptide formation over a wide range of initial reactant concentrations. Comparatively low initial reactant concentrations of $50 \mathrm{mM}$ resulted in $2.9 \%$ dialanine yield and reducing the amino acid concentration in the total mixture to even $2.5 \mathrm{mM}$ still resulted in extensive dipeptide formation. Although separate environments for the emergence of the first biomolecules and the first organisms are conceivable, high metal concentrations do not seem very favorable for the first organisms. In this study, it could be shown that peptides are formed in $\mathrm{SO}_{2}$ under strongly reduced salt and metal concentrations compared with the SIPF reaction in water. $\mathrm{CuCl}_{2}$ could be used in catalytic amounts and other additives like $\mathrm{NaCl}$ were not necessary at all. Most importantly, the simple reaction conditions lead to a highly exploitative conversion at room temperature. All these findings increase the plausibility of the solvent in a prebiotic context, which is further supported by the successful product formation using the Hadean mineral covellite instead of $\mathrm{CuCl}_{2}$. Accordingly, fewer reactants in minor concentrations at a lower temperature are required for efficient peptide condensation in $\mathrm{SO}_{2}$. The effectiveness of the reaction under simple conditions suggests a high potential for peptide formation in a volcanic $\mathrm{SO}_{2}$ environment.

\section{Methods}

Amino acid mixtures. For the reactions containing mixtures of amino acids, equimolar amounts of amino acids were homogenized by ball milling in a $20 \mathrm{~mL}$ stainless steel jar equipped with ten stainless steel balls (diameter $=10 \mathrm{~mm}$ ) at $400 \mathrm{rpm}$ for $10 \mathrm{~min}$ in the planetary ball mill Pulverisette 7 premium line (Fritsch $\mathrm{GmbH}$, Idar-Oberstein, Germany). The detailed list of sample weights can be found in the Supplementary Information.

Peptide condensation reactions. Peptide formation in aqueous solution was carried out in $4 \mathrm{~mL}$ glass vials with magnetic stir bar. To the respective amino acid mixture $(1.20 \mathrm{mmol}$ in total, $1.00 \mathrm{eq})$ urea $(72.1 \mathrm{mg}, 1.20 \mathrm{mmol}, 1.00 \mathrm{eq})$, and aqueous stock solutions of $\mathrm{NaCl}(2.64 \mathrm{~mL}, 5.00 \mathrm{M})$ and $\mathrm{CuCl}_{2}(360 \mu \mathrm{L}, 3.33 \mathrm{M})$ were added. The vials were sealed and placed in a metal block at $85^{\circ} \mathrm{C}$. The reactions were stirred for $21 \mathrm{~d}$ and samples were taken after 7 and $21 \mathrm{~d}$. All experiments were performed three times.

Reactions in $\mathrm{SO}_{2}$ (N38, 99.98\%, Air Liquide Germany) were performed in stainless steel pressure apparatuses (Supplementary Fig. 1). A $3.5 \mathrm{~mL}$ test tube equipped with a magnetic stir bar was filled with glycine $(90.1 \mathrm{mg}, 1.20 \mathrm{mmol}$, 1.00 eq.), L-alanine (106.9 mg, $1.20 \mathrm{mmol}, 1.00$ eq.), urea (72.1 mg, $1.20 \mathrm{mmol}, 1.00$ eq.), and $\mathrm{CuCl}_{2}(161.3 \mathrm{mg}, 1.20 \mathrm{mmol}, 1.00$ eq.) or optionally with covellite (114.7 mg, $20.9 \mathrm{mmol} / \mathrm{g}$ ). For reactions with large mixtures, the particular amino acid mixture consisting of $n$ amino acids ( $1.20 \mathrm{mmol}$ in total, 1.00 eq.), urea ( $72.1 \mathrm{mg}, 1.20 \mathrm{mmol}, 1.00 \mathrm{eq}$.), and $\mathrm{CuCl}_{2}$ (1/n eq.) was added to the test tube instead. The test tube was inserted into the pressure apparatus, evacuated, and refilled with nitrogen three times. At $-76^{\circ} \mathrm{C}, 3 \mathrm{~mL}$ of $\mathrm{SO}_{2}$ was condensed into the reaction chamber. The valves were closed, and the reaction carried out at room temperature under stirring for 1-21 d. Subsequently, the $\mathrm{SO}_{2}$ was condensed into the storage chamber and the remaining solid dried in vacuo. The solvent was reused up to five times for further reactions. The test tube was removed from the apparatus and the product mixture stored at $-18^{\circ} \mathrm{C}$ until analysis.

CE-MS/MS analysis. Before measurement, the samples were diluted according to the initial amino acid concentration. In all cases, the concentration of each amino acid of the mixture in the sample vial was $1 \mathrm{mM}$. The product mixtures were analyzed using an Agilent 7100 CE system coupled to a Thermo Scientific Q Exactive Plus mass spectrometer with a custom-made sheath-flow interface, which was described in a previous study ${ }^{62}$. The electrophoretic separations were performed in positive polarity mode at $25^{\circ} \mathrm{C}$ with an aqueous acetic acid solution (2 M) as background electrolyte (BGE). To avoid peptide adsorption linear polyacrylamide-coated capillaries with a total length of $80 \mathrm{~cm}$ were used whose preparation was described elsewhere ${ }^{67}$. Before their first utilization, a short piece of the outer polyimide coating was removed at the MS end of the capillaries and they were conditioned with deionized water $(2 \mathrm{~min})$, aqueous $\mathrm{H}_{3} \mathrm{PO}_{4}(10 \mathrm{mM}, 5 \mathrm{~min})$, deionized water $(2 \mathrm{~min})$, and BGE $(2 \mathrm{~min})$. Between measurements the capillaries were flushed again with aqueous $\mathrm{H}_{3} \mathrm{PO}_{4}(10 \mathrm{mM}, 30 \mathrm{~s})$, deionized water (1 min), and BGE $(2 \mathrm{~min})$. Sample injection was performed by applying $30 \mathrm{mbar}$ pressure for $10 \mathrm{~s}$. To separate the peptide mixture, a voltage of $30 \mathrm{kV}$ and a constant assisting pressure of 30 mbar was applied to the CE inlet. For establishing a stable electrospray, an external voltage of $3.2 \mathrm{kV}$ was applied to the stainless steel emitter while the sheath liquid was delivered at $3 \mu \mathrm{L} / \mathrm{min}$. The sheath liquid consisted of deionized water and isopropanol (50:50) with $0.05 \%$ formic acid.

Mass spectra were recorded in positive mode with a resolution of 70,000 in the mass range $\mathrm{m} / \mathrm{z} \quad 122-750$. The temperature of the ion transfer capillary was set to $140{ }^{\circ} \mathrm{C}$ while a minimal flow of sweep gas was applied. The S-lens RF level was adjusted to 50. For dipeptide fragmentation, data-dependent MS/MS measurements with inclusion lists containing all possible peptide products were performed. The MS/MS spectra were measured with a resolution of 17,500 using a normalized collision energy of $30 \%$. The mass spectra were evaluated using Thermo Xcalibur software 4.1.

CE analysis. Dipeptide quantification of the alanine-glycine system was performed using the Agilent $7100 \mathrm{CE}$ system. Before measurement, samples were diluted to an amino acid concentration of $10 \mathrm{mM}$. The analysis was conducted in positive polarity mode at $25^{\circ} \mathrm{C}$ using a conductivity detector. Separations were accomplished on bare fused silica capillaries with a total length of $80 \mathrm{~cm}$ and aqueous acetic acid $(2 \mathrm{M})$ as BGE by applying a voltage of $30 \mathrm{kV}$. Samples were injected by applying $30 \mathrm{mbar}$ for $10 \mathrm{~s}$. Calibration curves of GG, AG+GA, and AA were recorded in triplicates and 4-hydroxyproline $(100 \mu \mathrm{M})$ was used as internal standard. New capillaries were conditioned with deionized water, aqueous $\mathrm{NaOH}$ $(0.1 \mathrm{M})$, deionized water, and BGE (each $5 \mathrm{~min})$. Between measurements, capillaries were flushed with aqueous $\mathrm{NaOH}(0.1 \mathrm{M})$, deionized water, and BGE (each $2 \mathrm{~min}$ ). CE electropherograms were evaluated using CEval $0.6 \mathrm{~g}^{68}$ and OriginPro 2018G (see Supplementary Information, Section 2). 


\section{Data availability}

The authors declare that the main data supporting the findings of this study are available within the paper and its Supplementary Information files. Extra data are available from the corresponding author upon request.

Received: 26 June 2021; Accepted: 18 November 2021;

Published online: 10 December 2021

\section{References}

1. Frenkel-Pinter, M., Samanta, M., Ashkenasy, G. \& Leman, L. J. Prebiotic peptides: molecular hubs in the origin of life. Chem. Rev. 120, 4707-4765 (2020).

2. Miller, S. L. A production of amino acids under possible primitive earth conditions. Science 117, 528-529 (1953).

3. Parker, E. T. et al. Primordial synthesis of amines and amino acids in a 1958 Miller $\mathrm{H}_{2} \mathrm{~S}$-rich spark discharge experiment. Proc. Natl Acad. Sci. USA 108, 5526-5531 (2011).

4. Harada, K. \& Fox, S. W. Thermal synthesis of natural amino-acids from a postulated primitive terrestrial atmosphere. Nature 201, 335-336 (1964).

5. Zhang, X. et al. Prebiotic synthesis of glycine from ethanolamine in simulated archean alkaline hydrothermal vents. Orig. Life Evol. Biosph. 47, 413-425 (2017).

6. Martins, Z., Modica, P., Zanda, B. \& d'Hendecourt, L. L. S. The amino acid and hydrocarbon contents of the Paris meteorite: Insights into the most primitive CM chondrite. Meteorit. Planet. Sci. 50, 926-943 (2015).

7. Cronin, J. R. \& Pizzarello, S. Enantiomeric excesses in meteoritic amino acids. Science 275, 951-955 (1997).

8. Glavin, D. P. \& Dworkin, J. P. Enrichment of the amino acid L-isovaline by aqueous alteration on CI and CM meteorite parent bodies. Proc. Natl Acad. Sci. USA 106, 5487-5492 (2009).

9. Pizzarello, S., Schrader, D. L., Monroe, A. A. \& Lauretta, D. S. Large enantiomeric excesses in primitive meteorites and the diverse effects of water in cosmochemical evolution. Proc. Natl Acad. Sci. USA 109, 11949-11954 (2012).

10. Fox, S. W. \& Harada, K. Thermal copolymerization of amino acids to a product resembling protein. Science 128, 1214 (1958).

11. Rodriguez-Garcia, M. et al. Formation of oligopeptides in high yield under simple programmable conditions. Nat. Commun. 6, 8385-8391 (2015).

12. Ferris, J. P., Hill, A. R., Liu, R. \& Orgel, L. E. Synthesis of long prebiotic oligomers on mineral surfaces. Nature 381, 59-61 (1996).

13. Lambert, J.-F. Adsorption and polymerization of amino acids on mineral surfaces: a review. Orig. Life Evol. Biosph. 38, 211-242 (2008).

14. Surman, A. J. et al. Environmental control programs the emergence of distinct functional ensembles from unconstrained chemical reactions. Proc. Natl Acad. Sci. USA 116, 5387-5392 (2019).

15. Frenkel-Pinter, M. et al. Selective incorporation of proteinaceous over nonproteinaceous cationic amino acids in model prebiotic oligomerization reactions. Proc. Natl Acad. Sci. USA 116, 16338-16346 (2019).

16. Doran, D., Abul-Hija, Y. M. \& Cronin, L. Emergence of function and selection from recursively programmed polymerisation reactions in mineral environments. Angew. Chem. Int. Ed. 58, 11253-11256 (2019).

17. Canavelli, P., Islam, S. \& Powner, M. W. Peptide ligation by chemoselective aminonitrile coupling in water. Nature 571, 546-549 (2019).

18. Brack, A. Selective emergence and survival of early polypeptides in water Orig. Life Evol. Biosph. 17, 367-379 (1987).

19. Greenwald, J., Friedmann, M. P. \& Riek, R. Amyloid aggregates arise from amino acid condensations under prebiotic conditions. Angew. Chem. Int. Ed. 55, 11609-11613 (2016).

20. Stolar, T. et al. Mechanochemical prebiotic peptide bond formation. Angew. Chem. Int. Ed. 60, 12727-12731 (2021).

21. Schwendinger, M. G. \& Rode, B. M. Possible role of copper and sodium chloride in prebiotic evolution of peptides. Anal. Sci. 5, 411-414 (1989).

22. Jakschitz, T. A. E. \& Rode, B. M. Chemical evolution from simple inorganic compounds to chiral peptides. Chem. Soc. Rev. 41, 5484-5489 (2012).

23. Damer, B. \& Deamer, D. The hot spring hypothesis for an origin of life. Astrobiology 20, 429-452 (2020).

24. Mulkidjanian, A. Y., Bychkov, A. Y., Dibrova, D. V., Galperin, M. Y. \& Koonin, E. V. Origin of first cells at terrestrial, anoxic geothermal fields. Proc. Natl Acad. Sci. USA 109, E821-E830 (2012).

25. Matreux, T. et al. Heat flows in rock cracks naturally optimize salt compositions for ribozymes. Nat. Chem. 13, 1038-1045 (2021).

26. Ochiai, E.-I. The evolution of the environment and its influence on the evolution of life. Orig. Life 9, 81-91 (1978).

27. Hazen, R. M. Paleomineralogy of the Hadean Eon: A preliminary species list. Am. J. Sci. 313, 807-843 (2013).
28. Yamagata, Y., Watanabe, H., Saitoh, M. \& Namba, T. Volcanic production of polyphosphates and its relevance to prebiotic evolution. Nature 352, 516-519 (1991).

29. Šponer, J. E. et al. Emergence of the first catalytic oligonucleotides in a formamide-based origin scenario. Chem. Eur. J. 22, 3572-3586 (2016).

30. Saladino, R., Crestini, C., Pino, S., Costanzo, G., \& Di Mauro, E. Formamide and the origin of life. Phys. Life Rev. 9, 84-104 (2012).

31. Menor-Salván, C. \& Marín-Yaseli, M. R. Prebiotic chemistry in eutectic solutions at the water-ice matrix. Chem. Soc. Rev. 41, 5404-5415 (2012).

32. Gull, M., Zhou, M., Fernández, F. M. \& Pasek, M. A. Prebiotic phosphate ester syntheses in a deep eutectic solvent. J. Mol. Evol. 78, 109-117 (2014).

33. Kasting, J. F., Zahnle, K. J., Pinto, J. P. \& Young, A. T. Sulfur, ultraviolet radiation, and the early evolution of life. Orig. Life Evol. Biosph. 19, 95-108 (1989).

34. Walker, J. C. G. \& Brimblecombe, P. Iron and sulfur in the pre-biologic Ocean. Precambrian Res. 28, 205-222 (1985).

35. Marcq, E., Bertaux, J.-L., Montmessin, F. \& Belyaev, D. Variations of sulphur dioxide at the cloud top of Venus's dynamic atmosphere. Nat. Geosci. 6, 25-28 (2013).

36. Kasting, J. Earth's early atmosphere. Science 259, 920 (1993).

37. Sleep, N. H. The Hadean-Archaean environment. Cold Spring Harb. Perspect. Biol. 2, a002527 (2010).

38. Turner, J. et al. Record low surface air temperature at Vostok station, Antarctica. J. Geophys. Res. 114, 1-14 (2009).

39. Zahnle, K., Schaefer, L. \& Fegley, B. Earth's earliest atmospheres. Cold Spring Harb. Perspect. Biol. 2, a004895 (2010).

40. Kadoya, S., Krissansen-Totton, J. \& Catling, D. C. Probable cold and alkaline surface environment of the hadean earth caused by impact ejecta weathering. Geochem. Geophys. Geosyst. 21, e2019GC008734 (2020).

41. Hoffman, P. F., Kaufman, A. J., Halverson, G. P. \& Schrag, D. P. A Neoproterozoic snowball earth. Science 281, 1342-1346 (1998).

42. Kirschvink, J. L. et al. Paleoproterozoic snowball earth: extreme climatic and geochemical global change and its biological consequences. Proc. Natl Acad. Sci. USA 97, 1400-1405 (2000).

43. Kasting, J. F. \& Ackerman, T. P. Climatic consequences of very high carbon dioxide levels in the earth's early atmosphere. Science 234, 1383-1385 (1986).

44. Zahnle, K. et al. Emergence of a habitable planet. Space Sci. Rev. 129, 35-78 (2007).

45. Bergstrom, F. W. The boiling points of ammonia, sulfur dioxide and nitrous oxide. J. Phys. Chem. 26, 876-894 (1922).

46. Bergstrom, F. W. The vapor pressure of sulfur dioxide and ammonia. J. Phys Chem. 26, 358-376 (1922).

47. Kawai, D., McLendon, D. C., Kim, H.-J. \& Benner, S. A Hydroxymethanesulfonate from volcanic sulfur dioxide: a "Mineral" reservoir for formaldehyde and other simple carbohydrates in prebiotic chemistry. Astrobiology 19, 506-516 (2019).

48. Chen, F. \& Yang, D. Condensation of amino acids to form peptides in aqueous solution induced by the oxidation of sulfur(iv): an oxidative model for prebiotic peptide formation. Orig. Life Evol. Biosph. 37, 47-54 (2007).

49. Becker, S. et al. Unified prebiotically plausible synthesis of pyrimidine and purine RNA ribonucleotides. Science 366, 76-82 (2019)

50. $\mathrm{Xu}$, J. et al. Photochemical reductive homologation of hydrogen cyanide using sulphite and ferrocyanide. Chem. Commun. 54, 5566-5569 (2018).

51. Ranjan, S., Todd, Z. R., Sutherland, J. D. \& Sasselov, D. D. Sulfidic anion concentrations on early earth for surficial origins-of-life chemistry. Astrobiology 18, 1023-1040 (2018).

52. Nanda, J. et al. Emergence of native peptide sequences in prebiotic replication networks. Nat. Commun. 8, 434 (2017).

53. Mayr, H., Gorath, G. \& Bauer, B. Liquid sulfur dioxide as a lewis-acidic solvent for the alkylation and alkoxyalkylation of allylsilanes. Angew. Chem. Int. Ed. 33, 788-789 (1994)

54. Danger, G., Plasson, R. \& Pascal, R. Pathways for the formation and evolution of peptides in prebiotic environments. Chem. Soc. Rev. 41, 5416-5429 (2012).

55. Lohrmann, R. Formation of urea and guanidine by irradiation of ammonium cyanide. J. Mol. Evol. 1, 263-269 (1972).

56. Lowe, C. U., Rees, M. W. \& Markham, R. Synthesis of complex organic compounds from simple precursors: formation of amino-acids, amino-acid polymers, fatty acids and purines from ammonium cyanide. Nature 199, 219-222 (1963).

57. Gull, M., Omran, A., Feng, T. \& Pasek, M. A. Silicate-, magnesium ion-, and urea-induced prebiotic phosphorylation of uridine via pyrophosphate; revisiting the hot drying water pool scenario. Life 10, 122 (2020).

58. Burcar, B. et al. Darwin's warm little pond: a one-pot reaction for prebiotic phophorylation and the mobilization of phosphates from minerals in a ureabased solvent. Angew. Chem. Int. Ed. 55, 13249-13253 (2016).

59. Lohrmann, R. \& Orgel, L. E. Urea-inorganic phosphate mixtures as prebiotic phosphorylating agents. Science 171, 490-494 (1971). 
60. Hua, L., Zhou, R., Thirumalai, D. \& Berne, B. J. Urea denaturation by stronger dispersion interactions with proteins than water implies a 2-stage unfolding. Proc. Natl Acad. Sci. USA 105, 16928-16933 (2008).

61. Zhang, Z., Qu, Y. \& Dovichi, N. J. Capillary zone electrophoresis-mass spectrometry for bottom-up proteomics. Trends Anal. Chem. 108, 23-37 (2018).

62. Sauer, F., Sydow, C. \& Trapp, O. A robust sheath-flow CE-MS interface for hyphenation with Orbitrap MS. Electrophoresis 41, 1280-1286 (2020).

63. Higgs, P. G. \& Pudritz, R. E. A thermodynamic basis for prebiotic amino acid synthesis and the nature of the first genetic code. Astrobiology 9, 483-490 (2009).

64. Trifonov, E. N. The origin of the genetic code and of the earliest oligopeptides. Res. Microbiol. 160, 481-486 (2009).

65. Bellmaine, S., Schnellbaecher, A. \& Zimmer, A. Reactivity and degradation products of tryptophan in solution and proteins. Free Radic. Biol. Med. 160, 696-718 (2020).

66. Schnitzer, T., Wiesner, M., Krattiger, P., Revell, J. D. \& Wennemers, H. Is more better? A comparison of tri- and tetrapeptidic catalysts. Org. Biomol. Chem. 15, 5877-5881 (2017).

67. Zhu, G., Sun, L. \& Dovichi, N. J. Thermally-initiated free radical polymerization for reproducible production of stable linear polyacrylamide coated capillaries, and their application to proteomic analysis using capillary zone electrophoresis-mass spectrometry. Talanta 146, 839-843 (2016).

68. Dubský, P., Ördögová, M., Malý, M. \& Riesová, M. CEval: All-in-one software for data processing and statistical evaluations in affinity capillary electrophoresis. J. Chromatogr. A 1445, 158-165 (2016).

\section{Acknowledgements}

We acknowledge financial support from the Ludwig-Maximilians-University Munich the Max-Planck-Society (Max-Planck-Fellow Research Group Origins of Life), the Volkswagen Stiftung (Initiating Molecular Life), the Deutsche Forschungsgemeinschaf DFG/German Research Foundation (Project-ID 364653263-TRR 235, Emergence of Life) and Germany's Excellence Strategy (ORIGINS, EXC-2094-390783311).

\section{Author contributions}

O.T. conceived the idea and directed the project. O.T., F.S., and M.H. designed the experiments. F.S. and C.A.L. performed the experiments in aqueous salt solution. M.H. and C.S. carried out the reactions in $\mathrm{SO}_{2}$. F.S. and M.H. developed and performed the analytical separation and identification methods. C.S., F.S., and A.F.S. validated and performed the quantification. F.S., M.H., C.S., and A.F.S. evaluated the data. M.H., F.S. and O.T. wrote the paper. All authors discussed the results and edited the paper.

\section{Funding}

Open Access funding enabled and organized by Projekt DEAL.

\section{Competing interests}

The authors declare no competing interests.

\section{Additional information}

Supplementary information The online version contains supplementary material available at https://doi.org/10.1038/s41467-021-27527-7.

Correspondence and requests for materials should be addressed to Oliver Trapp.

Peer-review information Nature Communications thanks Leroy Cronin and the other anonymous reviewers for their contribution to the peer review of this work. Peerreviewer reports are available.

Reprints and permission information is available at http://www.nature.com/reprints

Publisher's note Springer Nature remains neutral with regard to jurisdictional claims in published maps and institutional affiliations.

\begin{abstract}
(c) (i) Open Access This article is licensed under a Creative Commons Attribution 4.0 International License, which permits use, sharing, adaptation, distribution and reproduction in any medium or format, as long as you give appropriate credit to the original author(s) and the source, provide a link to the Creative Commons license, and indicate if changes were made. The images or other third party material in this article are included in the article's Creative Commons license, unless indicated otherwise in a credit line to the material. If material is not included in the article's Creative Commons license and your intended use is not permitted by statutory regulation or exceeds the permitted use, you will need to obtain permission directly from the copyright holder. To view a copy of this license, visit http://creativecommons.org/ licenses/by/4.0/.
\end{abstract}

(C) The Author(s) 2021 